\title{
Prospective Randomized Controlled Study Comparing Caudal Block versus Dorsal Penile Nerve Block as Postoperative Analgesia in Children Presented for Penile Surgery
}

\author{
SALMA E. KANDIL, M.Sc.; YASSER A. RAGHEB, M.D. and SAMEH A. ISMAIEL, M.D. \\ The Department of Anesthesiology and Intensive Care, Faculty of Medicine, Tanta University, Tanta, Egypt
}

\begin{abstract}
Background: Caudal block is recommended for analgesia during and after surface operation on the penis, for example circumcision and hypospadias repair. The aim of this study was to compare caudal block versus dorsal penile block in children undergoing penile surgery, regarding duration and quality of post-operative analgesia.
\end{abstract}

Aim of the Study: To compare caudal block versus dorsal penile block in children undergoing penile surgery, our primary outcome was the duration of postoperative analgesia while our secondary outcome was the quality of post-operative analgesia.

Patients and Methods: 60 children, ASA I-II, 1-4 year's old undergoing penile surgery under general anesthesia were enrolled in the study. Children were randomly classified into two groups: (Group I) (penile group $=30$ patients) received a penile block using a mixture of lidocaine $3 \mathrm{mg} / \mathrm{kg}(2 \%)$ and plain bupivacaine $1 \mathrm{mg} / \mathrm{kg}(0.25 \%)$ on each side, Group II (caudal block group $=30$ patients) patients of this group received a caudal block using a mixture of lidocaine $3 \mathrm{mg} / \mathrm{kg} \mathrm{(2 \% )}$ and plain bupivacaine $1 \mathrm{mg} / \mathrm{kg}(0.25 \%)$. Assessment of postoperative pain will be done by the Faces Pain Scale which is a self-report measure of pain intensity developed for children. It was adapted from the Faces Pain Scale to make it possible to score the sensation of pain on the widely accepted 0-to-10 metric, "0" equals "no pain" and "10" equals "very much pain". This done immediately postoperative and every $2 \mathrm{H}$ until $6 \mathrm{H}$ post-operative.

Results: Faces pain score was significantly lower in group $\mathrm{II}$ at $2 \mathrm{H}, 4 \mathrm{H}$ and $6 \mathrm{H}$ post-operative with increase on the duration of block in Group II, also there was significant decrease in heart rate in Group II at $30 \mathrm{~min}, 45 \mathrm{~min}, 75 \mathrm{~min}$, $90 \mathrm{~min}, 105 \mathrm{~min}, 120 \mathrm{~min}$ and $135 \mathrm{~min}$ respectively from the start of surgery so there was significant increase of bradycardia and need of atropine in group.

Conclusions: Caudal block seemed to be more effective in reducing post-operative pain score and decreasing the need

Correspondence to: Dr. Salma E. Kandil, The Department of Anesthesiology and Intensive Care, Faculty of Medicine, Tanta University, Tanta, Egypt of rescue analgesia with prolongation of the duration of the block.

Key Words: Caudal block-Penile block-Lidocaine Marcaine.

\section{Introduction}

PENILE surgery constitutes an important portion of pediatric urological surgery. Post-operative analgesia is an important issue especially in the pediatric population. Successful pain relief decreases morbidity and the need for narcotic analgesics, also allow mobilization in the early post-operative period [1].

Penile block, caudal block, penile ring infiltration, topical local anesthetic application and administration of paracetamol are commonly employed for pain relief after penile surgery [2] .

The Dorsal Penile Nerve Block (DPNB) was first described for use in neonatal circumcision in 1978. Since then, multiple studies have demonstrated both its safety and efficacy. In a recent prospective report there are short term complication as failure to achieve adequate anesthesia and analgesia, bleeding, hematomas, skin sloughing and infection [3].

Penile blocks have became more commonly used in pediatric patients as adjunct to general anesthesia for procedures on the penis such as circumcision, hypospadias repair, urethral dilation and papilloma laser fulguration. It provides anesthesia to the distal $2 / 3$ of the penis only [4] .

Caudal block is one of the most useful and most often performed regional blocks in pediatric anesthesia. They are suitable for lower extremity, perineal, inguinal, and lower abdominal surgery. 
Properly performed, caudal block is a rapid and safe technique that leads to better patient comfort and potentially better outcome, and it could also decrease the anesthesia time. However, certain complication can occur with the use of caudal block as intravascular injection, epidural hematoma, epidural abscess, neural injury or urinary retention $[2,5]$.

\section{Patients and Methods}

This randomized controlled double blinded study was carried out in Tanta University Hospital, Pediatric Surgery Department for duration of 6 month (from May 2016 to November 2016) after approval of Ethical Committee (approval code: 30881/04/16) and obtaining a written informed consent from parents of all participant, all data of patients were confidential with secret codes and private file for each patient. All given data were used for current medical research only, this study included sixty child patients aged from 1-4 years, ASA status I or II undergoing penile surgery. Any child with parent refusal, bleeding tendency, genital malformations, local anesthetic allergy, infection at injection site, sacrococcygeal abnormalities and children with delayed developmental milestone was excluded from the study, the patients were randomized using a computer generated randomization to one of two equal groups: Penile group (Group I) and caudal group (Group II). Fig. (1).

Pre-operative sedation was established by oral chloral hydrate in a dose of $25 \mathrm{mg} / \mathrm{kg}$ then, patients were transported to operating room, with insertion of 22 gauge peripheral cannula to establish IV access, then patient were monitored by 3 leads ECG, oxygen saturation and noninvasive blood pressure, induction of anesthesia was carried out by sevoflurane $8 \%$ and oxygen at flow rate ( 4 $\mathrm{L} / \mathrm{min}$ ), then, airway was secured by suitable sized laryngeal mask airway. Then, general anesthesia was maintained by sevoflurane inhalation of $2 \%$ MAC and oxygen: Air (1:1) while patients left spontaneously breathing.

\section{Group I: Penile block (technique):}

This technique was performed in supine position, in sterile manner after identifying symphysis pubis as an anatomical landmark and cleaning scrotum and suprapubic area with povidone iodine, the penis was pulled down during the block to open the pear shaped spaces on each side of the suspensory ligament. The block was performed by carrying out 2 injections, one on each side. Injection sites were in the middle between lower edge of symphysis pubis and the penis 0.5 to $1 \mathrm{~cm}$ lateral to the midline, needle used was 22 gauge intramuscular needles. The needle was inserted perpendicular to the skin and advanced downwards. Increase in resistance on the needle was felt in the depth of approximately $1-2 \mathrm{~cm}$ as the fascia was a layer of fat over the pubis in infants making assessment of depth more difficult, when performing the block, the needle must be advanced further by $0.5-1 \mathrm{~cm}$ to make sure it is well in the space. After negative aspiration, a block was initiated by a mixture of lidocaine $3 \mathrm{mg} / \mathrm{kg}(2 \%)$ and plain bupivacaine $1 \mathrm{mg} / \mathrm{kg}(0.25 \%)$ on each side, it should be very easy to inject if the needle sits in correct space. Resistance on injection or blood on aspiration means malposition of the needle.

\section{Group II: Caudal block (technique):}

A left lateral position was obtained with the upper hip flexed $90^{\circ}$, the lower one only $45^{\circ}$ before palpating the landmarks, the region was swabbed in a craniocaudal direction with povidone Iodine solution to reduce the amount of bacteria, intensive skin disinfection, sterile drapes, and the use of sterile gloves should be standard for every caudal blockage, the upper posterior iliac spine and the sacral hiatus form the edges of an equilateral triangle. It should be emphasized that the sacral hiatus always lies cranial to the natal cleft, and in the lateral position is higher than the apparent midline because of the dead weight of the buttocks, epidural puncture was achieved in the most proximal region of the sacral hiatus with the needle inclined $45^{\circ}$ to $60^{\circ}$ to the skin. The palpating index finger of the left hand lied on the spinous process of S4, after perforation of the tectorial membrane, which occludes the sacral hiatus, usually felt as a clear give, the needle was minimally advanced, no more than 1 to $3 \mathrm{~mm}$, to avoid a bloody puncture or an intrathecal injection. Injection of air was done to identify correct epidural placement of the needle tip then injection of the local anesthetics was done by a mixture of lidocaine $3 \mathrm{mg} / \mathrm{kg}(2 \%)$ and plain bupivacaine $1 \mathrm{mg} / \mathrm{kg}(0.25 \%)$.

\section{Measurements:}

The following data were measured and recorded by an anesthetist who was not participating in the study.

1- Demographic data (age in years, body weight in $\mathrm{kg}$, duration of surgery in minutes and type of surgery).

2- Hemodynamic parameters, mean arterial blood pressure $(\mathrm{mmHg})$ and heart rate (beat/minute) was recorded at baseline (before induction of anesthesia) and at $5 \mathrm{~min}$ after nerve block then every $15 \mathrm{~min}$ till discharge from Post Anesthesia 
Care Unit (PACU) patient who developed bradycardia (decreased HR below 70 beat/minute) was treated by atropine $0.1 \mathrm{mg}$ IV and re-assessed with documentation of number of patient who required atropine in each group.

3- Assessment of post-operative pain was done by the Faces Pain Scale which is a self-report measure of pain intensity developed for children. It was adapted from the Faces Pain Scale to make it possible to score the sensation of pain on the widely accepted 0 -to- 10 metric, "0" equals "no pain" and "10" equals "very much pain". This was done at emergency and every $2 \mathrm{H}$ until $6 \mathrm{H}$ post-operative.

Patient with pain score more than 4 (moderate to sever pain) received rescue analgesia in the form of morphine $0.1 \mathrm{mg} / \mathrm{kg}$ IV and paracetamol $10 \mathrm{mg} / \mathrm{kg}$ IV infusion, repeated if needed considering that the total dose of morphine not exceeding $0.3 \mathrm{mg} / \mathrm{kg}$ and the total dose of paracetamol dose not exceeding $20 \mathrm{mg} / \mathrm{kg}$.

4- Duration of the block, which was defined as time (interval in hours) for the first patient requirement for postoperative analgesics after recovery from anesthesia. If no analgesic was needed in the first $24 \mathrm{~h}$, the duration will be set to be $24 \mathrm{~h}$.

5- Incidence of post-operative complication (pruritus, nausea, vomiting, incontinence and bradycardia) was recorded.

\section{Results}

Regarding the demographic data as age, sex, body weight, type and duration of surgery there was no significant difference between both groups $(p$-value >0.05).

Regarding to hemodynamic changes, intergroup comparison in heart rate revealed that there was no significant difference ( $p$-value $>0.05$ ) at base line, $15 \mathrm{~min}$ and $60 \mathrm{~min}$ from the start of surgery, then there was significant difference between the 2 groups ( $p$-value $<0.05$ ) at $30 \mathrm{~min}, 45 \mathrm{~min}, 75 \mathrm{~min}$, $90 \mathrm{~min}, 105 \mathrm{~min}, 120 \mathrm{~min}$ and $135 \mathrm{~min}$ respectively from the start of surgery, so there was significant decrease in heart rate in Group II (Table 1) \& Fig. (2), also intergroup comparison in the mean arterial blood pressure revealed that there was no significant difference in the mean value of mean arterial blood pressure at any time interval ( $p$-value $>0.05$ ).

Intergroup comparison of faces pain score revealed that: Faces pain score was significantly lower in Group II at $2 \mathrm{H}, 4 \mathrm{H}$ and $6 \mathrm{H}$ post-operative ( $p$-value <0.05) (Table 2) \& Fig. (3).

Duration of the block was ranged from 1-5 hours in Group I and 1-10 hours in Group II with a mean value of $2.57 \pm 1.10$ hours and $6.07 \pm 2.10$ hours respectively, comparison between two groups revealed that there was statistically increase ( $p$ value $<0.05$ ) on the duration of block in Group II (Table 3) \& Fig. (4).

Regarding need of rescue analgesia, in Group I, 11 patients $(36.7 \%)$ needed rescue analgesia while in Group II, 3 patients $(10 \%)$ needed rescue analgesia, so there was significant increase ( $p$ value $<0.05$ ) of need of rescue analgesia in Group I (Table 4).

Regarding incidence of complication, in Group I, 1 patient (3.3\%) complain of pruritis while in Group I, 3 patients (10\%) complain of pruritis, so the two group was comparable ( $p$-value $>0.05$ ), in Group I, 1 patient $(3.3 \%)$ complain of nausea and vomiting while in Group II, 3 patients (10\%) complain of nausea and vomiting, so there was no significant difference between the two group ( $p$ value >0.05), in Group I, 1 patient (3.3\%) complain of incontinence while in Group $\prod, 4$ patient (13.3\%) complain of incontinence, so the two group was comparable ( $p$-value $>0.05$ ), in Group I, 1 patient (3.3\%) complain of bradycardia and need atropine while in Group $\prod, 8$ patients (26.7\%) complain of bradycardia and need atropine, so there was significant increase ( $p$-value $<0.05$ ) of bradycardia and of atropine in Group $\prod$ (Table 5).

Table (1): Intergroup comparison of heart rate (b/minute).

\begin{tabular}{|c|c|c|c|c|}
\hline \multirow{2}{*}{$\begin{array}{l}\text { Heart rate } \\
(\mathrm{b} / \mathrm{min})\end{array}$} & \multirow{2}{*}{$\begin{array}{c}\text { Group I } \\
\text { Mean } \pm \text { SD }\end{array}$} & \multirow{2}{*}{$\begin{array}{c}\text { Group II } \\
\text { Mean } \pm \text { SD }\end{array}$} & \multicolumn{2}{|c|}{ Test } \\
\hline & & & $t$ & $p$-value \\
\hline T0 & $126.67 \pm 8.28$ & $126.33 \pm 10.42$ & 0.137 & 0.891 \\
\hline $\mathrm{T} 1$ & $126.27 \pm 9.44$ & $122.83 \pm 6.91$ & 1.607 & 0.113 \\
\hline $\mathrm{T} 2$ & $127.33 \pm 8.98$ & $121.93 \pm 6.51$ & 2.667 & $0.010 *$ \\
\hline $\mathrm{T} 3$ & $126.73 \pm 8.60$ & $121.07 \pm 6.75$ & 2.839 & $0.006^{*}$ \\
\hline $\mathrm{T} 4$ & $124.70 \pm 7.07$ & $120.30 \pm 16.67$ & 1.331 & 0.188 \\
\hline $\mathrm{T} 5$ & $123.53 \pm 7.88$ & $116.00 \pm 18.86$ & 2.019 & $0.048 *$ \\
\hline T6 & $124.93 \pm 8.49$ & $111.97 \pm 22.45$ & 2.959 & $0.004 *$ \\
\hline $\mathrm{T} 7$ & $123.70 \pm 8.75$ & $112.00 \pm 20.64$ & 2.859 & $0.006 *$ \\
\hline $\mathrm{T} 8$ & $124.13 \pm 8.01$ & $112.07 \pm 18.49$ & 3.281 & $0.002 *$ \\
\hline T9 & $124.23 \pm 7.96$ & $112.67 \pm 17.95$ & 3.226 & $0.002 *$ \\
\hline $\begin{array}{l}\text { T0: Base lin } \\
\text { T1: } 15 \mathrm{~min} . \\
\mathrm{T} 2: 30 \mathrm{~min} . \\
\mathrm{T} 3: 45 \mathrm{~min} .\end{array}$ & & $\begin{array}{l}60 \mathrm{~min} . \\
75 \mathrm{~min} . \\
90 \mathrm{~min}\end{array}$ & & $\begin{array}{l}105 \mathrm{~min} . \\
120 \mathrm{~min} . \\
135 \mathrm{~min} .\end{array}$ \\
\hline
\end{tabular}


Enrollment Assessed for eligibility ( $\mathrm{n}=78)$

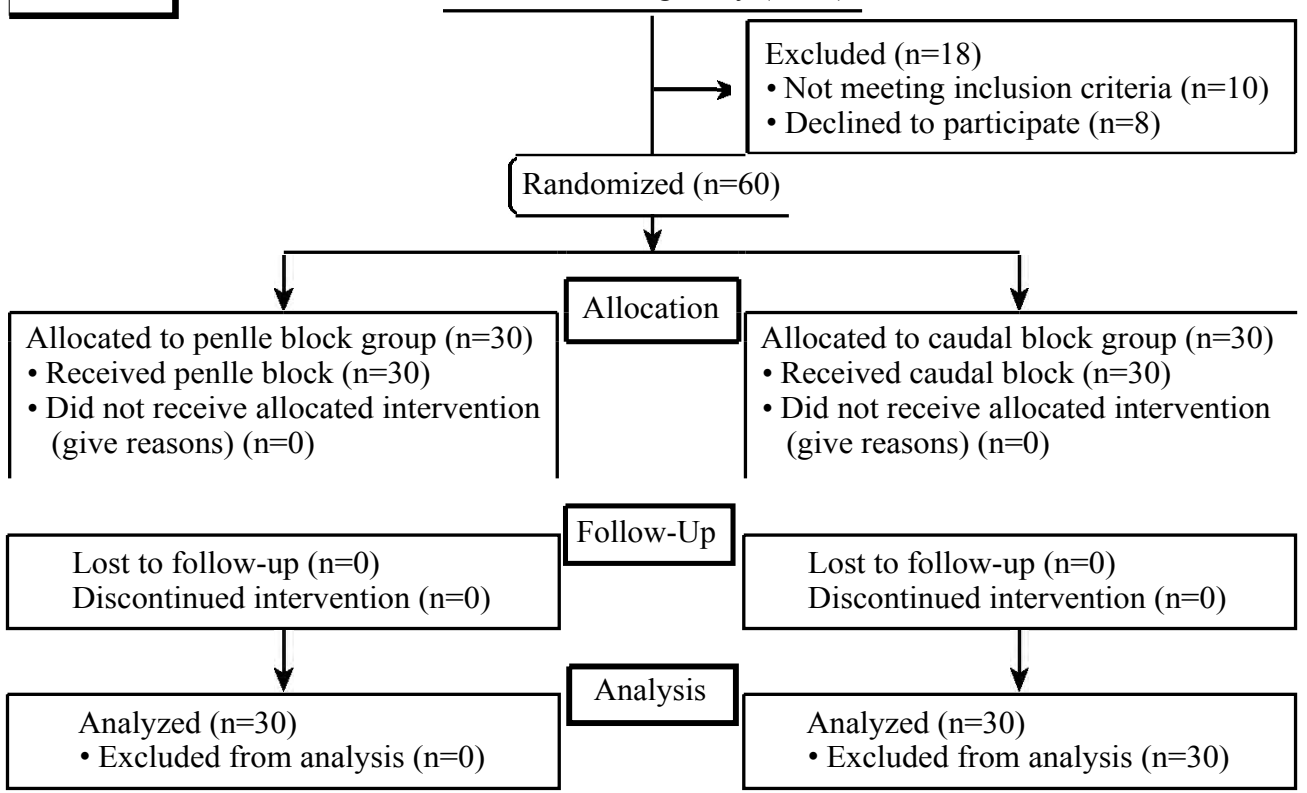

Fig. (1): Consert flow chart of our study.

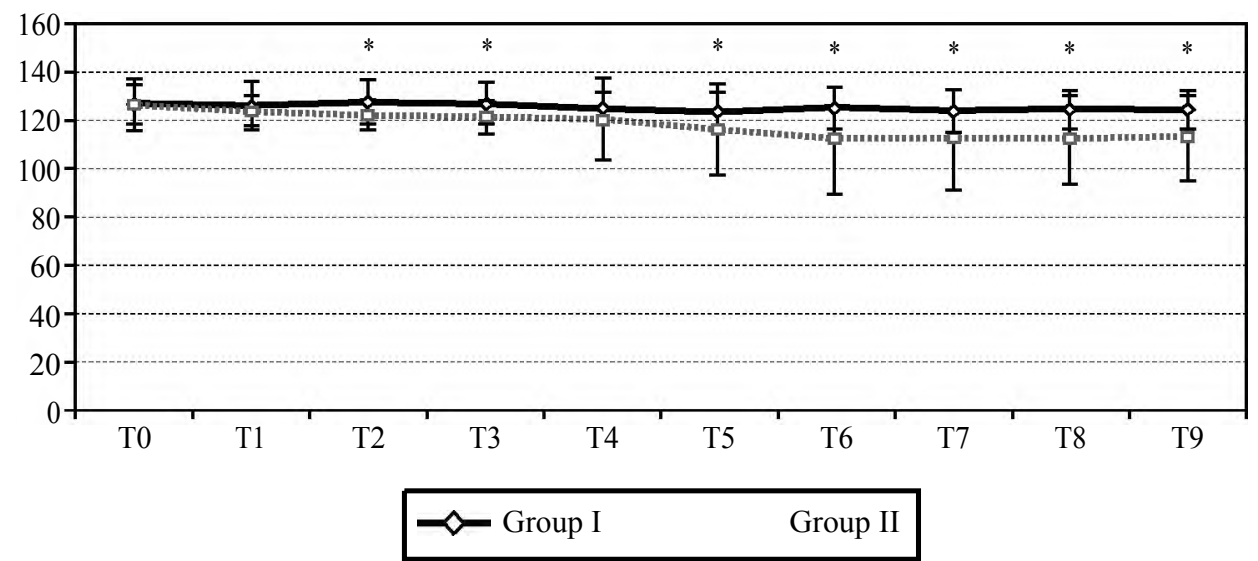

Fig. (2): Intergroup comparison of heart rate (b/minute).

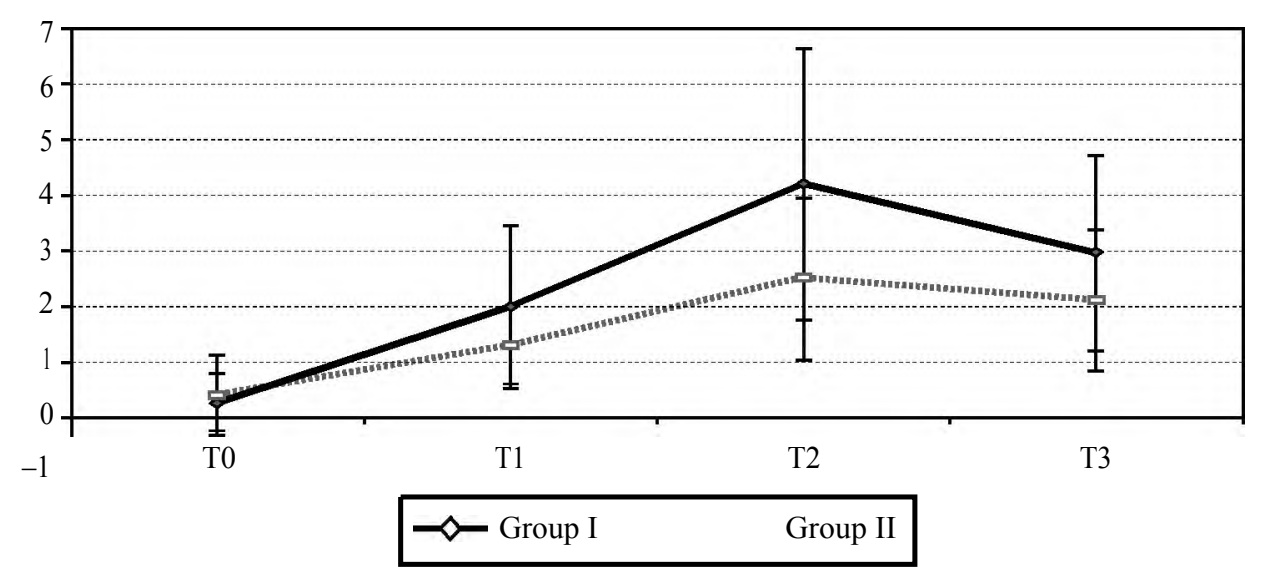

Fig. (3): Intergroup comparison of faces pain score in the two groups.

* : Denotes significant decrease in faces pain scale $(p$-value $<0.05)$ in Group $\Pi$.

T0: Immediately post-operative. $\quad$ T2: $4 \mathrm{H}$ post-operative.

T1: $2 \mathrm{H}$ post-operative. $\quad$ T3: $6 \mathrm{H}$ post-operative. 


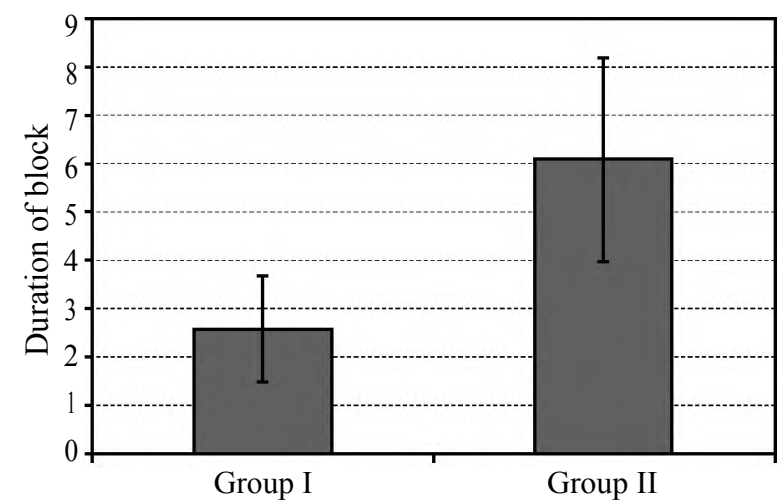

Fig. (4): Intergroup comparison of duration of the block.

Table (2): Intergroup comparison of faces pain score.

\begin{tabular}{|c|c|c|c|c|}
\hline \multirow{2}{*}{ FPS } & \multirow{2}{*}{$\begin{array}{c}\text { Group I } \\
\text { Mean } \pm \text { SD }\end{array}$} & \multirow{2}{*}{$\begin{array}{c}\text { Group II } \\
\text { Mean } \pm \text { SD }\end{array}$} & \multicolumn{2}{|c|}{ Test } \\
\hline & & & $t$ & $p$-value \\
\hline T0 & $0.27 \pm 0.52$ & $0.4 \pm 0.72$ & 0.819 & 0.416 \\
\hline $\mathrm{T} 1$ & $2 \pm 1.46$ & $1.3 \pm 0.7$ & 2.364 & $0.021 *$ \\
\hline $\mathrm{T} 2$ & $4.2 \pm 2.43$ & $2.5 \pm 1.46$ & 3.290 & $0.002 *$ \\
\hline $\mathrm{T} 3$ & $2.97 \pm 1.77$ & $2.1 \pm 1.27$ & 2.179 & $0.033^{*}$ \\
\hline
\end{tabular}

Table (3): Intergroup comparison of duration of the block.

\begin{tabular}{llllll}
\hline \multirow{2}{*}{ Groups } & \multicolumn{2}{l}{ Duration of block (hours) } & & \multicolumn{2}{c}{ Test } \\
\cline { 2 - 3 } \cline { 5 - 6 } & Range & Mean $\pm \mathrm{SD}$ & & $t$ & $p$-value \\
\hline Group I & $1.0-5.0$ & $2.57 \pm 1.10$ & 8.080 & $<0.001^{*}$ \\
Group II & $1.0-10.0$ & $6.07 \pm 2.10$ & & \\
\hline *: Denotes significant increase in duration of block $(p$-value $<0.05)$ \\
in Group $\Pi$.
\end{tabular}

Table (4): Intergroup comparison of need of rescue analgesia.

\begin{tabular}{|c|c|c|c|c|c|c|c|c|c|}
\hline & \multicolumn{7}{|c|}{ Group I Group II Total } & \multicolumn{2}{|c|}{ Chi-square } \\
\hline & \multicolumn{7}{|c|}{$\bar{N} \% \overline{N \%} N \%$} & \multicolumn{2}{|c|}{$x^{2} x_{\text {-value }}$} \\
\hline $\begin{array}{l}\text { - Need of } \\
\text { rescue } \\
\text { analgesia }\end{array}$ & 11 & \multicolumn{2}{|c|}{36.73} & 31 & 0.09 & \multicolumn{2}{|c|}{15.0} & 4.565 & $0.033 *$ \\
\hline \multicolumn{10}{|c|}{$\begin{array}{l}\text { *: Denotes significant increase in need of rescue analgesia ( } p \text {-value } \\
<0.05 \text { ) in Group I. }\end{array}$} \\
\hline \multicolumn{10}{|c|}{ Table (5): Intergroup comparison of incidence of complication. } \\
\hline & \multicolumn{3}{|c|}{$\begin{array}{l}\text { Group } \\
\text { I }\end{array}$} & \multicolumn{2}{|c|}{$\begin{array}{l}\text { Group } \\
\text { II }\end{array}$} & \multicolumn{2}{|c|}{ Total } & \multicolumn{2}{|c|}{ Chi-square } \\
\hline & & $\mathrm{N}$ & $\%$ & $\mathrm{~N}$ & $\%$ & $\mathrm{~N}$ & $\%$ & $\chi^{2}$ & $p$-value \\
\hline - Pruritis & & 1 & 3.3 & 3 & 10.0 & 4 & 6.7 & 1.071 & 0.301 \\
\hline $\begin{array}{l}\text { - Nausea \& } \\
\text { vomiting }\end{array}$ & & 1 & 3.3 & 3 & 10.0 & 4 & & 1.071 & 0.301 \\
\hline - Incontinence & ce & 1 & 3.3 & 4 & 13.3 & 5 & 8.3 & 1.964 & 0.161 \\
\hline - Bradycardia & $\mathrm{a}$ & 1 & 3.3 & 8 & 26.7 & 5 & 8.3 & 4.706 & $0.030 *$ \\
\hline $\begin{array}{l}\text { - Need of } \\
\text { atropine }\end{array}$ & & 1 & 3.3 & 8 & 26.7 & 5 & 8.3 & 4.706 & $0.030 *$ \\
\hline
\end{tabular}

\section{Discussion}

Optimal analgesia following ambulatory surgery is an important matter for patient satisfaction and it reduces unnecessary hospital admissions. Circumcision and hypospadias are commonly performed operations in male children. Various methods are being used for postoperative pain of this operation such as Dorsal penile nerve block (DPNB), caudal block, topical analgesia and also systemic Non-Steroidal Anti-inflammatory Drugs (NSAIDs) or opioids. It has been shown that local anesthetic techniques are more effective than opioids [6] . Caudal block and DPNB both provide effective analgesia for circumcision $[7,8]$.

Our study compared the duration and quality of post-operative analgesia of penile block versus caudal block using bupivacaine and lidocaine in penile surgery including hypospadias repair and circumcision under general anesthesia.

In the current study, the patient's characteristics were comparable in the two groups (the age, the body weight, the duration of surgery and the type of surgery).

Regarding to hemodynamic changes, heart rate was not significantly different in the two groups till 30min after the block, when there was a decrease in the heart rate in caudal group compared with penile group. While there was no significant difference between the two groups in the mean value of mean arterial blood pressure at any time interval.

Regarding pain assessment which done by using faces pain score, our result showed that postoperative pain scores in penile group were significantly higher from the second hour and thereafter when compared to caudal group.

Regarding to the duration of the block in our study, there was significant increase in the duration of the block in caudal group when compared to penile group.

Regarding to need of rescue analgesia in our study, there was statistically increase in need of rescue analgesia in penile group. So the block was more effective and of longer duration in caudal group compared to penile group.

Regarding to the incidence of complication in our study, there was no significant difference between the two groups in (pruritis, nausea, vomiting and incontinence), while there was significant increase in incidence of bradycardia in caudal group as 5 patient had bradycardia and needed 
atropine while 1 patient only in penile group had bradycardia and needed atropine.

In agreement with our study: Ebru et al., [9] who compared three different techniques of preventive analgesia (caudal block technique, dorsal penile nerve block and who were administered subcutaneous morphine) according duration and quality of post-operative analgesia before circumcision operations in male children aged 6-12 years old, they concluded that, caudal block decrease post-operative pain measured by CHEOPS score more than penile block and administration of subcutaneous morphine with more decrease in heart rate in caudal block than penile block. Also the incidence of complication was comparable between caudal and penile block. Also, Panda et al., [10] who compared the success rates and the hemodynamic changes of caudal block and dorsal penile nerve blocks for circumcision. They demonstrated that, there was a higher success rate with caudal block and less post-operative hemodynamic changes among 1-5 years old pediatric patients presenting for day case circumcision.

Moreover, Patel, et al., [11] who aimed to compare postoperative analgesia and complication of caudal block versus Dorsal Penile Nerve Block (DPNB) in children undergoing circumcision. They found that the difference of post-operative pain between the two groups was insignificant for 2 hours then there was decrease in FLACC pain score in caudal group after 2 hours when compared to penile group, they concluded that the duration of post-operative analgesia was more in caudal group than that of DPNB also the supplementary analgesic need was minimized with insignificant incidence of complication in both groups. In addition, Mahin et al., [12] who aimed to compare caudal and penile nerve block using bupivacaine in post-operative pain control in hypospadias repair in children. They demonstrated that, caudal block has more success rate and more quality also longer duration of postoperative analgesia when compared to penile block. However, there was increased in motor block and the risk of alternation of hemodynamic parameters (blood pressure and heart rate) remains higher with caudal block. Also in their retrospective study, Sandemann et al., [13] who reported the effectiveness and safety of Dorsal Penile Nerve Block (DPNB), Caudal Epidural Analgesia (CEA) and ultrasound-guided Dorsal Penile Nerve Block (DPNB-US). The DPNB group required a larger total dose of morphine, and had longer recovery ward stays than CEA or DPNBUS groups. Time to first analgesia was greatest for the CEA group while there was no significant difference between time to first analgesia for DPNB and DPNB-US. In addition, Margetts et al., [14] they concluded that both techniques provided effective post-operative analgesia; but caudal block had a longer post-operative analgesia period and there was no difference between the groups in the incidence of vomiting.

In controversy to our study: Telgarsky et al., 2013, [6] who aimed to evaluate the post-operative analgesic efficacy of penile block, caudal block and intravenous paracetamol administration following circumcision. They demonstrated that penile block had more post-operative analgesic effect when compared with caudal block, the difference with our study may be due to usage of a different technique to assess the pain as they used CHEOPS scoring system, while we used faces pain score. They were in agree with our results in absence of major complication with either caudal or penile block. Also, Beyaz et al., [15] who aimed to compare the efficacy of caudal block versus Dorsal Penile Block (DPNB) under general anesthesia for children undergoing circumcision. They concluded that DPNB and caudal block provided similar postoperative analgesic effects without major complications for children under general anesthesia, this difference with our study may be due to using different drug as they used levobupivacaine while we used bupivacaine. Moreover, Cyna and Middleton [9] who compared the effects of caudal epidural analgesia with other forms of post-operative analgesia following circumcision in boys between 28 days and 16 years, there was no difference was seen between caudal and parenteral analgesia in the need for rescue or other analgesia or on the incidence of nausea and vomiting no difference in the need for rescue or other analgesia was seen for caudal compared with Dorsal Nerve Penile Block (DNPB) no differences were seen between caudal block and DNPB in the incidence of nausea and vomiting, they concluded that, differences in the need for rescue or other analgesia could not be detected between caudal, parenteral and penile block methods. In addition, Weksler, et al., [2] who aimed to compare caudal and penile block for postoperative analgesia in children undergoing circumcision with respect to efficacy, complication rates. They found that the penile block shortened the induction-incision time and enabled earlier discharge home compared with caudal block. The conclusion was, penile and caudal block are equally effective for post circumcision analgesia and neither is associated with serious complications. Anesthesiologist preference should be the deciding factor in choosing one technique over the other. 


\section{Conclusion:}

The use of either penile or caudal block in children presented for penile surgery were effective in the postoperative analgesia without major complication. Caudal block seemed to be more effective in reducing postoperative pain score and decreasing the need of rescue analgesia with prolongation of the duration of the block. Penile block seems to be associated with lesser incidence of bradycardia.

\section{Acknowledgment:}

This research was carried out without funding.

\section{Conflicts of interest:}

No conflicts of interest declared.

\section{Authors' contributions:}

All authors had equal role in design, work, statistical analysis and manuscript writing.

\section{References}

1- SEMSROTH M., GABRIEL A., SAUBERER A., et al.: Regional anesthetic procedures in pediatric anesthesia. Anesthesia, 43: 55-72, 1994.

2- WEKSLER N., ATIAS I., KLEIN M., et al.: Is penile block better than caudal epidural block for post circumcision analgesia? J. Anesth., 19: 36-9, 2005.

3- STANG H.J., SNELLMAN L.W., CONDON L.M., et al.: Beyond Dorsal Penile Nerve Block: A More Humane Circumcision. Pediatrics, 100: 3, 1997.

4- PRADLO M., SONNER J.M. and CLINICIAN P.: Manual of Anethesia Practice, Cambridge University Press, 2012.

5- ENAS M. and BOSAT E. BOSATB: Single-injection penile block versus caudal block in penile pediatric surgery, Ain-Shams Journal of Anesthesiology, 07: 42833, 2014.

6- TELGARSKY B., KAROVIC D., WASSERMANN O., et al.: Penile block in children, our first experience. Bratisl Lek Listy, 107: 320-2, 2006.
7- IRWIN M.G. and CHENG W.: Comparison of subcutaneous ring block of the penis with caudal epidural block for post-circumcision analgesia in children. Anaesth. Intensive Care, 24: 365-7, 1996.

8- HOLDER K.J., PEUTRELL J.M. and WEIR P.M.: Regional anaesthesia for circumcision. Subcutaneous ring block of the penis and subpubic penile block compared. Eur. J. Anaesthesiol., 14: 495-8, 1997.

9- CANAKCI E., YAGAN O. and TAS N.: Comparison of preventive analgesia techniques in circumcision cases: Dorsal penile nerve block, caudal block, or subcutaneous morphine? Journal of Pakistan Medical Association, 67: 159-65, 2017.

10- SHEHU P.U., ADAMU A.S., TANIMU S., et al.: Comparison of the Success Rates and Haemodynamic Changes of Caudal Block. And Dorsal Penile Nerve Block in Paediatric Day-Case Circumcision. African Journal of Anaesthesia and Intensive Care, 16: 1, 2016.

11- PATEL S., SHAH S. and PARMAR H.: Comparison of post-operative analgesic efficacy of caudal block versus dorsal penile nerve block with bupivacaine for circumcision in children. International Journal of Medical Science and Public Health, 4: 233-6, 2015.

12- SEYEDHEJAZI1 M., AZERFARIN R., AZEMI1 F., et al.: Comparing caudal and penile nerve blockade using bupivacaine in hypospadias repair surgeries in children. African Journal of Paediatric Surgery, 8: 294-7, 2011.

13- SANDEMAN D.J., REINER D., DILLEY A.V., et al.: A retrospective audit of three different regional anaesthetic techniques for circumcision in children. Anaesth Intensive Care, 38: 519-24, 2010.

14- MARGETTS L., CARR A., McFADYEN G., et al.: A comparison of caudal bupivacaine and ketamine with penile block for paediatric circumcision. Eur. J. Anaesthesiol., 25: 1009-13, 2008.

15- BEYAZ S.G.: Comparison of Post-operative Analgesic Efficacy of Caudal Block versus Dorsal Penile Nerve Block with Levobupivacaine for Circumcision in Children. Korean J. Pain, 24: 31-5, 2011. 


\section{دراسة مقارنة مستقبلية بين تثبيط الآعصاب الذيلية

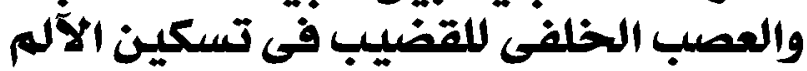 ما بعل جراحات القضيب القيبين}

تشكل جراحات القضيب جزءا مهما من جراحات المسالك البقلية للأطفال. ويعتبر تسكين بعد الجراحة تضية ذات آهمية خاصة. فإن تخفيف

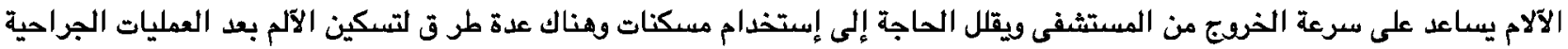

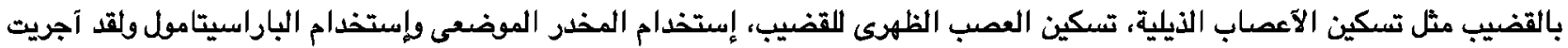

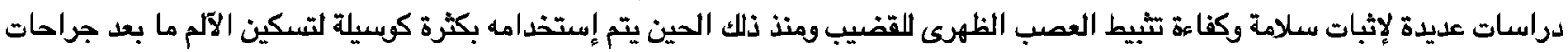
القضيب كما يعتبر تثبيط الآعصاب الذيلية واحد من آفضل وسيائل التخدير المستخدمة في الآطفال حيث يتم إستخدامه في في العمليات بمنطقة

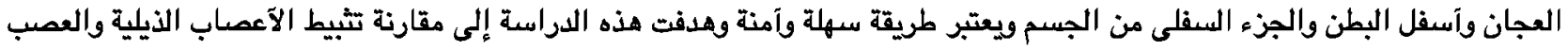
الظهرى للقضيب في تسكين الآلم ما بعد جراحات القضيب وإثتملت على ستين مريض بين سنة وآربع سنين وقسمت إلى مجموعتين، المجموعة

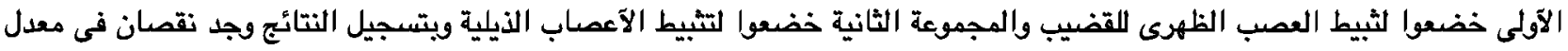

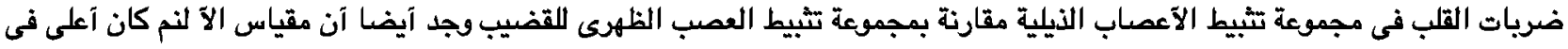

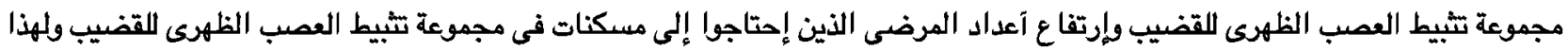

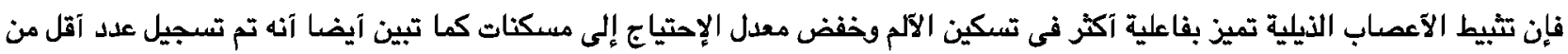

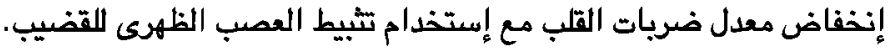

